\title{
The portrait of a teacher from the innovative higher education - students' viewpoint
}

\author{
Kseniya Mertins $^{1, a}$, Veronika Ivanova ${ }^{1}$, Kurkan Nataliya ${ }^{1}$, Ivan Zatonov ${ }^{1}$ \\ ${ }^{1}$ National Research Tomsk Polytechnic University, 30 Lenin Avenue, Tomsk 634034, Russia
}

\begin{abstract}
The issue of quality engineering education aimed at resource efficiency and sustainable development worldwide is quite topical nowadays. One of the main components of the educational environment is a teacher, whose role has changed significantly over the past decade: from a translator to a facilitator. In addition, it is worth considering that students begin to play an increasingly active role in the educational process. They set requirements to the quality, contents and innovative techniques which facilitate the development of competencies. The survey "Ideal teacher at an innovative technical university" was conducted at National Research Tomsk Polytechnic University. This paper presents the comparative analysis of universal and professional competencies of "ideal" and "real" teachers based on the students' viewpoint. The portrait of a teacher, who is able and has enough facility to foster students' competitive skills to confront sustainable development challenges including "green engineering" through collaboration, was drafted.
\end{abstract}

\section{Introduction}

According to the Federal State Educational Standard of Higher Education, students are the active participants in the process of developing and monitoring the educational environment. One of the leading roles in the development process belongs to a teacher who is no longer a translator of the academic knowledge but a students' partner who has a facility to develop the creative environment for an educational process implementing the contemporary educational technologies and selecting the most appropriate strategy [1]. In this case, the activity is defined as a partnership, a co-management of a student and a teacher with the subject-to-subject relationship. The pedagogical interaction directly depends on the way how subjects can understand and feel about each other and what they expect from this relationship. The differences in expectation cover the wide range of problems: from trustworthy values to the quality of education and academic achievements [2]. Different scientists try to find out the the teacher profile students most prefer [3]. There is an oppinion that students are more affected by their teachers' social behaviors in comparison to their instructional behaviors. [3-9]. Investigations show that students prefer teachers who value them, establish effective communication with them, who are interested in their problems and have an equalitarian and democratic attitude, as well as teachers who use methods and techniques which are appropriate for their educational level and can increase their motivation, who love their jobs, carry out their duties in an enjoyable and principled manner and have a command of their areas.

\section{Methodology}

The study has been designed as a survey model. In the study, a qualitative approach has been adopted.

\section{The purpose of the paper}

The purpose of this paper is the analysis of the students' view on the important characteristics of a teacher at a technical university, their gender and social role as well. The following tasks were required to be completed in the research:

1. The arrangement of data obtained from the survey.

2. An experimental study of students' ideas about professionally important characteristics of a teacher.

3. A comparison of the «ideal» and «actual» teacher concepts.

\section{The Analysis of Survey Data}

177 students of the Institute of Non-Destructive Testing of Tomsk Polytechnic University were the respondents of the survey with the participation of the following

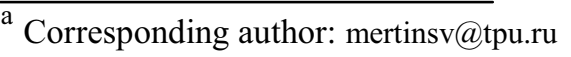


categories: $54,2 \%$ females, $45,8 \%$ males, among them $22,6 \%$ are the 1 st year students, $11,3 \%$ - the 2 nd year, $23,2 \%$ - the $3 \mathrm{~d}$ year, $22,6 \%$ - the 4 th year, $14,7 \%$ are the 1 st year postgraduates, $5,6 \%-$ the 2 nd year postgraduates.

Students were invited to answer the questions concerning the gender preference when choosing a teacher, the professional as well as personal qualities of a teacher. Besides, students were invited to provide characteristics of an ideal teacher using just three adjectives. The survey results are presented in tables and charts below.

\subsection{Students' points of view on the ideal age for a teacher}

The first question was related to the students' preferences for the age of teachers. Students were invited to mark the

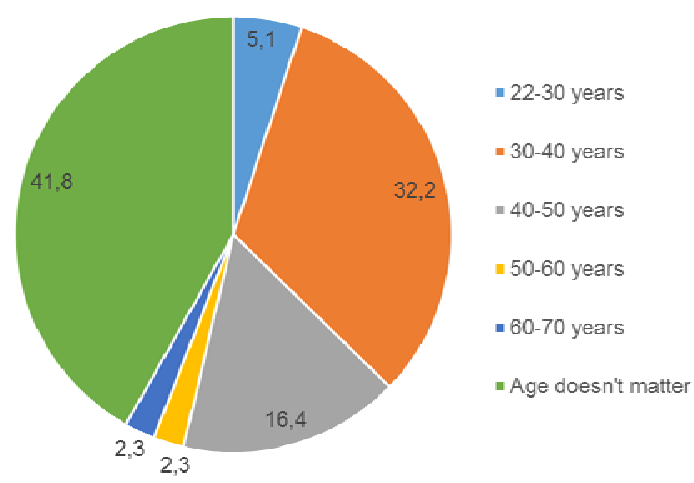

range of the age which is most desirable for their teachers. The option "the age does not matter" was provided as well. Moreover, students were asked to clarify their choice.

Fig. 1. The pie chart demonstrating the students' preferences for the age of a teacher (the year of study was not considered).

The chart reveals that over $40 \%$ of respondents paid no regard to the age of a teacher. At the same time, 32\% believed that teachers at the ages from 30 to 40 provided the most optimized approach to teaching. This decision was mostly reasoned by the following moments: teacher's experience, innovative approach to the subject teaching, the ability to understand student audience, using the social networks as a tool for communication, presentations, e-excursions and tests online based on latest trends in science and technology, professional confidence. The professional experience in scientific and pedagogical fields was of little importance for $16 \%$ of respondents, who would like to be taught by teachers aged $40-50$. It is worth noting that none of the $3 \mathrm{~d}$ and 4 th year students as well as the 2 nd year postgraduates marked the range $22-30$. The age of a teacher did not matter for $41,8 \%$ of all respondents, least attention to the teacher's age was paid by the $3 \mathrm{~d}$ and the 4 th year students $-48,8 \%$ and $52,5 \%$, respectively. The age of a teacher made difference mostly for the 2 nd year students: only $15 \%$ decided for the option "The age doesn't matter". This choice was justified by the students' commitment to quality education, which does not depend on the age. The students' preferences for a teacher with regard to the age are summarized in Table 1.

The table demonstrates that the teachers of the ages $22-30$ were preferred by the 1 st, the 2 nd year students as well as the 1st year postgraduates. Such a decision was provided due to following aspects: sense of equality, easy rapport, opportunity to contact, amiability, a contemporary approach to teaching, close relationship with the university (the teachers of these ages have recently graduated using the innovative technologies, requirements, standards, sources of information), youth, and ability to understand students. Answering the next question «Quality education - high-level demands ratio of an ideal teacher», the same respondents selected the «experienced (who is good at subject and provides quality education) but too rigorous teacher, as seniors considered». They did not express any preferences to the gender of a teacher: $50 \%$ pointed that the gender of their teacher did not matter for them if he/ she is a positive person; other $50 \%$ marked the option «gender is not important, if a teacher provides quality education». Most respondents $-75 \%$ - selected this age category (22-30) were female.

Table 1. Students' choice of a teacher depending on the teacher's age with regard to the year of study $(\%)$.

\begin{tabular}{|c|c|c|c|c|c|c|}
\hline 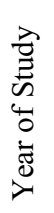 & 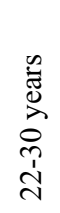 & 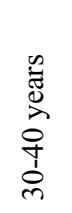 & 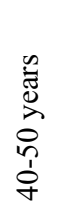 & 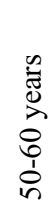 & 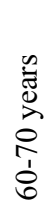 & 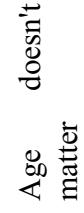 \\
\hline $1^{\text {st }}$ & 7,5 & 27,5 & 17,5 & 5 & 0 & 42,5 \\
\hline $2^{\text {nd }}$ & 20 & 40 & 25 & 0 & 0 & 15 \\
\hline $3^{\text {rd }}$ & 0,0 & 31,7 & 12,2 & 4,9 & 2,4 & 48,8 \\
\hline $4^{\text {th }}$ & 0,0 & 27,5 & 17,5 & 0 & 2,5 & 52,5 \\
\hline $1^{\mathrm{st}}$ & 7,7 & 38,5 & 11,5 & 0 & 7,7 & 34,6 \\
\hline $2^{\text {nd }}$ & 0 & 40 & 20 & 0 & 0 & 40 \\
\hline
\end{tabular}

The table demonstrates that the teachers of the ages $22-30$ were preferred by the 1 st, the 2 nd year students as well as the 1st year postgraduates. Such a decision was provided due to following aspects: sense of equality, easy rapport, opportunity to contact, amiability, a contemporary approach to teaching, close relationship with university (the teachers of these ages have recently graduated using the innovative technologies, requirements, standards, sources of information), youth, and ability to understand students. Answering the next question «Quality education - high-level demands ratio of an ideal teacher», the same respondents selected the «experienced (who is good at subject and provides 
quality education) but too rigorous teacher, as seniors considered». No preferences to the gender of a teacher were expressed by them: $50 \%$ pointed that the gender of their teacher did not matter for them if he/ she is a positive person; other $50 \%$ marked the option «gender is not important, if a teacher provides quality education». Most respondents $-75 \%$ - selected this age category (22-30) were female.

$17 \%$ of the surveyed students considered a teacher aged from 40 to 50 as the most efficient one. The following aspects were given to support this choice: experience (personal, professional, pedagogical), a long employment history, high-level demands, clarity in presenting information, openness to the world with their research, a positive manner of teaching, relevant activity, wisdom, ability to discipline and motivate students, etc. Everyone who selected this age category chose the «experienced (who is good at subject and provides quality education) but too rigorous teacher, as seniors considered».

The least amount of preference was given for the ages $50-60$ and $60-70-2,3 \%$ per each age category. The reason for this is that the teachers at these ages are highly skilled in a certain field.

\subsection{Quality education - a high-level demands ratio of an ideal teacher in the students' opinion}

The summary of students' answers about the preferred characteristics of a teacher is presented in table 2. Based on the results obtained, it can be concluded that the students are motivated to get good education and training.

Table 2. Student's answers to the questions about the teacher's personality.

\begin{tabular}{|c|c|}
\hline $\begin{array}{l}\text { Preference for an experienced (who is skilled at } \\
\text { her/his subject and able to provide quality education) } \\
\text { but too rigorous teacher, as seniors considered }\end{array}$ & $68.9 \%$ \\
\hline $\begin{array}{l}\text { Preference for a teacher with poor workplace } \\
\text { discipline and a lack of experience who is prone to } \\
\text { skip classes, comes late for work, gives the } \\
\text { assessment and scores for the subject without } \\
\text { providing progress/ final tests, just on the basis of } \\
\text { students' attendance at classes, not interested in } \\
\text { student's achievements (with regards to seniors' } \\
\text { answers) }\end{array}$ & $3.4 \%$ \\
\hline $\begin{array}{l}\text { Preference for a teacher who is a real expert in his } \\
\text { field, but not strict and can hardly motivate students } \\
\text { to learn the subject (students ignore the information } \\
\text { provided, a teacher meets student's requests to leave } \\
\text { classes earlier, not to give tasks for self-study, etc.) }\end{array}$ & $7.9 \%$ \\
\hline Never thought about this & $19.8 \%$ \\
\hline
\end{tabular}

It is worth noting that the number of students who prefer an «experienced teacher» rises with each year of study: from $50 \%$ to $77,5 \%$ among undergraduates and $100 \%$ of postgraduates. The results indicate the achievements of students as future specialists in the field of their qualification and the increase of responsibility for getting a degree.

\subsection{The students' preference for a teacher on the basis of gender identity}

All respondents were asked to decide which gender of a teacher is more comfortable for them to communicate in the process of education. In addition, two additional alternatives were provided «gender makes no difference if a teacher provides quality education», and «gender makes no difference if a teacher has got a positive character». The results are presented in the chart below which shows that $54 \%$ of respondents were focused on getting excellent education so a teacher, first of all, should be «a source of knowledge», a real expert in her/his field, and her/his gender identity was not important in that case. $26 \%$ paid attention to personal characteristics of a teacher, 17\% preferred being taught by a male, and just $3 \%$ - by a female.

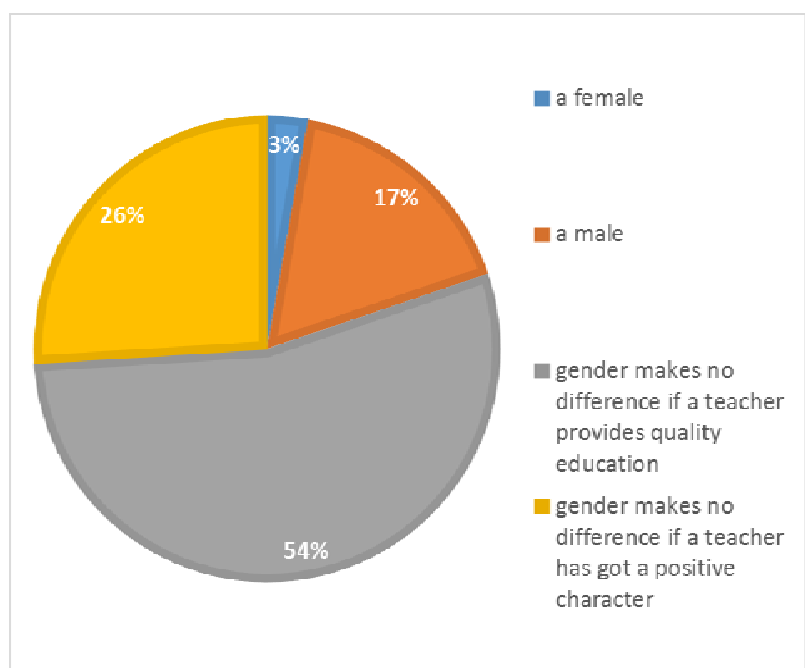

Fig. 2. The pie chart demonstrates the students' preferences for the gender of a teacher (the year of study was not considered).

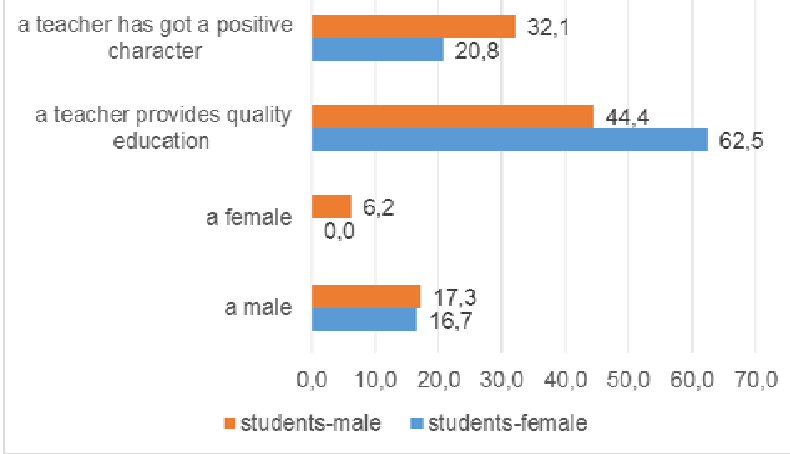

Fig 3. Students' preferences for the teacher gender depending on the gender of respondents.

The analysis of students' preferences depending on the teacher's gender (with regard to the gender of respondents) is presented below. Respondents of both 
genders emphasized the facility to provide quality education as the main characteristic for the university teacher.

It is worth noting that the preference for a male teacher was expressed by the equal amount (\%) of male and female respondents, while a female teacher was preferred only by male students.

\subsection{The students' preference for a teacher on the basis of the academic rank and a scientific degree}

According to the results obtained, the social rank of a teacher (her/his academic and scientific degrees) was of minor importance for most of the respondents (the chart ...). For $62 \%$ of respondents claimed that the essence of the information provided was the most crucial aspect, and $22 \%$ of respondents pointed out that the personal characteristics of a teacher are of great importance for them.

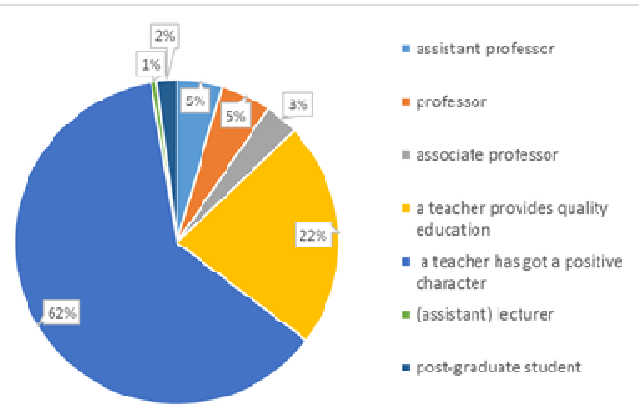

Fig 4. Students' preferences for the teacher on the basis of the academic rank and a scientific degree.

\section{Descriptive characteristics of an ideal teacher}

According to the students' opinion, the most significant characteristics for a teacher are: consciousness and intelligence (25 students), kindness (19 students), responsibility (13), being interesting (9), proficiency (8), sensibility, sociability, wisdom (7), consideration (5), charisma (4). Among the professional characteristics the following were marked: fairness (26), experience (15), determination (14), high-skills (8), being good at her/his subject (5), toughness, engagement, creativity (4), etc.

Moreover, not only the character adjectives were provided to describe a teacher personality - students were asked to select from the following list: a professional, an expert, a born teacher, a ripe scholar, excellent knowledge of the subject, relevant requirements, and clear communication of information, accessible explanations, transfer of relevant knowledge, practice-awareness, ability to provide knowledge before requiring it from students.

Among the free-format adjectives provided to describe an ideal teacher, the following personal adjectives were the most popular: conscious and kind 25 students, interesting - 9, sociable -7 , and professional characteristics as well: fair - 26 students, experienced -15 , determined -14 , educated -8 .

This choice of characteristics for an ideal teacher was determined by values and cultural environment of students as well as by their life and professional goals.

\section{Conclusion}

Based on the survey results, the ideal teacher portrait in education was compound as follows: a person preferably at the ages from 30 to 40 , who works at the university (as an assistant as well) and has a great experience. $\mathrm{S} / \mathrm{He}$ knows her/his Ps and Qs and provides quality education, but $\mathrm{s} /$ he is too rigorous, as seniors concern. However, the ideal teacher always consults the students on the matter of teaching techniques. The most appropriate adjectives assigned to an ideal teacher by students were: conscious and intelligent, kind, responsible, interesting, skilled, sensible, sociable, wise, considerate, charismatic. Among the professional characteristics, the following adjectives were chosen: fair, experienced, determined, high skilled, good at her/his subject, tough, engaged, creative. An ideal teacher is able and has enough facility to foster students' competitive skills to confront sustainable development challenges including "green engineering" through collaboration. The results of this survey are the basis for developing the strategy of increasing the quality of education.

\section{References}

1. P. Spooren, B. Brockx, and Dimitri Mortelmans, Rev. of ed. res., 83 (4), 598-642 (2013)

2. A. Nouri Belhaj, M. L. B. Abderrahman, International Journal of Higher Education, 4 (3), (2015)

3. M. Dilekmen, Psych. R., 108(1), 45-53 (2011)

4. K. Goh, Aust. J. of Ed. and Dev. Psychology, 14, 159166 (2014)

5. RH Heck, R Mahoe, Int. J.of Ed. Man., 24(1), 56-72 (2010)

6 G. Hilton, M.A. Flores, L Niklasson, T.D., 17(4), 431447 (2013)

7. A Jacob, Int. J.of Ed. L. P., 7(3), 1-13 (2012)

8 K.A. Khandelwal, Int. J. of T. and L. in H. Ed., 21(3), 299-309 (2009).

9 T. Hosgorur Ant., 19(3), 819-828 (2015) 